Estudos Multiespécies: uma breve análise da teoria e de suas aplicações.

Revista Ensaios, vol. 13, jul-dez de 2018. ISSN 2175-0564.

\title{
Estudos Multiespécies: uma breve análise da teoria e de suas aplicações
}

\author{
Thais Fernandes Pereira ${ }^{1}$
}

Resumo: Este artigo pretende trazer uma análise dos estudos multiespécies, das teorias às aplicações. Essa literatura pressupõe que as ciências naturais estão longe de ser a única forma de conhecer as vidas de outras espécies. Desse modo, toma para si a observação através da imersão na vida de criaturas antes deixadas às margens dos estudos antropológicos - tais como animais, plantas e fungos - e preocupa-se em entender as relações construídas entre diferentes espécies que se entrelaçam dentro de um mesmo ambiente.

Palavras Chaves: Antropologia, Estudos Multiespécies, Natureza e Cultura.

\section{Multispecies Studies: A brief analysis of the theory and its applications}

Abstract: In this paper we intend to bring an analysis of multispecies studies, from the theories to the applications. This literature presupposes that the natural sciences are far from the only way of knowing the lives of other species. In this way it takes observation by immersing itself in the life of creatures once left on the margins of anthropological studies such as animals, plants, and fungi - and is concerned with understanding the relationships built up between different species that intertwine within the same environment.

Keywords: Anthropology, Multispecies Studies, Nature and Culture

1 Universidade de São Paulo (USP), Graduação em Ciências Sociais, São Paulo, SP, Brasil. thais.fernandes.pereira@usp.br. 
Estudos Multiespécies: uma breve análise da teoria e de suas aplicações.

Revista Ensaios, vol. 13, jul-dez de 2018. ISSN 2175-0564.

Este artigo tem como objetivo abordar uma temática recente ao qual se convencionou chamar estudos multiespécies. Trata-se de um campo que, desdobrando-se da antropologia em específico e das ciências sociais de modo geral, teve uma série de repercussão em diversos países e apresenta-se em expansão também no Brasil. Há uma articulação entre os estudos animais, a etnologia indígena e a antropologia da ciência e tecnologia. Estes estudos se voltam, através de diversos pontos de partida, teórica e metodologicamente, à compreensão das espécies não humanas.

O artigo é constituído de quatro seções mais introdução e considerações finais. A segunda seção dedica-se a tentar situar o debate, subjacente aos estudos multiespécies, a respeito da dicotomia entre natureza e cultura, a partir de dois autores que são uma importante referência sobre o assunto dentro da antropologia: Bruno Latour e Tim Ingold. A terceira seção por sua vez, é constituída por três partes, e pretende abordar três diferentes perspectivas da relação humano-animal, são elas: os defensores dos direitos dos animais, o perspectivismo ameríndio, e a questão da antropomorfização. A quarta seção é uma análise sobre os estudos multiespécies propriamente, e pretende introduzir o leitor à teoria e suas principais acepções, principalmente através do artigo escrito por Thom Van Dooren, Eben Kirskey e Ursula Münster, que introduz o volume de maio de 2016 da revista Environmental Humanities, dedicado aos estudos multiespécies. Finalmente a quinta seção, subdividida em duas, propõe-se a comentar etnografias com seres não humanos: cogumelos, florestas e animais de laboratório.

Ao invés de introduzir o leitor diretamente aos estudos que levam o título deste artigo, tentou-se trilhar um caminho de introdução, comentando brevemente teorias que são pressupostos teóricos que interagem com a construção do pensamento multiespécie para logo depois entrar de fato nesse campo. Selecionou-se autores e conceitos, pois apesar de não ser possível dar conta da totalidade dos conteúdos existentes sobre o assunto, é possível tecer pontos de partida.

\section{Dicotomia cultura e natureza e antropologia simétrica}


Estudos Multiespécies: uma breve análise da teoria e de suas aplicações.

Revista Ensaios, vol. 13, jul-dez de 2018. ISSN 2175-0564.

É interessante situar o debate a respeito da dicotomia entre natureza e cultura dentro da antropologia, visto este ser um importante ponto de partida para os estudos multiespécies. Para isso, abordarei dois autores recentes que constituem referências importantes dentro desse tema, são eles, Bruno Latour e Tim Ingold.

Bruno Latour desenvolve em seu livro, Jamais Fomos Modernos, uma primeira formulação do que chamou de "antropologia simétrica" (LATOUR,1994), recebendo influências que vão desde o conceito de rizoma, elaborado por Deleuze e Guattari, passando pelo dispositivo de Michel Foucault, além de estudos sobre ciência e tecnologia, filosofia das ciências e sociologia do conhecimento. Latour se tornou referência no estudo das ciências e técnicas propondo uma transversalidade das disciplinas, situada numa intersecção entre sociologia e ciências exatas, "assumindo como objeto de estudo os processos que emergem da inovação científica e técnica: a chamada Antropologia das Ciências." (FREIRE, 2006, p.47).

O princípio da simetria generalizada, formulado em meio a essas perspectivas, entende que tanto a natureza quanto a sociedade devem ser interpretadas a partir de um quadro comum, ou mesmo plano, e nunca separadamente. Trata-se de um erro depreender o mundo das coisas em si, de um lado, e o mundo dos homens entre si, de outro, como se as ambas não fizessem parte de um mesmo efeito de redes heterogêneas que, apesar de não serem compostas dos mesmos elementos, podem ser descritas da mesma maneira.

De maneira semelhante à dupla humano e não humanos deve ser ultrapassada, visto que o que há é interação, "o social é uma rede heterogênea, constituída não apenas de humanos, mas também de não-humanos, de modo que ambos devem ser igualmente considerados" (FREIRE, 2006, p.49). Ou seja, já que todas as nossas ações no mundo são mediadas por objetos não humanos, estes devem ser igualmente reconhecidos e colocados em pauta, na tentativa de entendimento a respeito dos humanos.

A relação entre humanos e animais está presente nos trabalhos etnográficos realizados por Tim Ingold, como entre os criadores de rena da Lapônia, os Skolts do norte da Finlândia. Para o autor, a dualidade natureza e cultura aparece na tradição ocidental como uma dada tendência a se pensar a partir de dicotomias, como corpo e espírito, amor e ódio, emoção e razão etc., sendo a concepção de ser humano apenas herança desse pensamento dualista 
Estudos Multiespécies: uma breve análise da teoria e de suas aplicações.

Revista Ensaios, vol. 13, jul-dez de 2018. ISSN 2175-0564.

(INGOLD, 1995), e aponta para a necessidade de ir além dessa forma de pensamento, estudando os organismos sem desconectá-los abstratamente de seus ambientes de origem. Ingold (2011) refuta a noção, em suas palavras, superficial, de que os seres humanos iniciam a vida biologicamente iguais e se diferenciam culturalmente. Para o autor, a constituição dos seres se dá como processo de desenvolvimento que ocorre na medida em que se vive. Nesse sentido, as variações de habilidades ou mesmo culturais, não são inatas e nem adquiridas, mas desenvolvidas pelos organismos através de práticas no ambiente. Posto isto, é de interesse dessa perspectiva compreender os seres (humanos e não humanos) em sua relação com o ambiente. Isto não implica, no entanto, um determinismo às condições naturais, mas que o humano é parte constitutiva do meio e vice-e-versa.

Outro ponto importante de Ingold é pensar as noções de evolução e história, e natureza e cultura em diálogos entre si. Em seu texto "Sobre a distinção entre Evolução e História" (2006), o autor parte do incômodo em relação à precedência da História da humanidade (com $\mathrm{H}$ maiúsculo) em relação à história natural (com h minúsculo), que seria a evolução. Argumenta que essa separação implica pensar que, em algum momento, a humanidade foi o único organismo natural que transpôs a barreira da natureza, podendo a partir de então, construir uma história em separado de tudo aquilo que a torna verdadeiramente "humana", como a linguagem, a arte, os simbolismos, a tecnologia e etc. (ANDRADE, 2016).

Dissolver a dicotomia entre natureza e cultura seria reconhecer e pensar a história como formas de moldar as condições de vida de seus sucessores, que apenas está em continuidade com as mesmas ações de todo o mundo orgânico. Nesse sentido, todos os organismos são pessoas humanas (INGOLD, 2006).

Seguindo a reflexão de Ingold sobre dicotomias fundadoras do pensamento ocidental, e relevante para o tema tratado neste artigo, no livro "Humanidade e Animalidade" (1995) há uma reflexão a respeito de como essas duas noções são dependentes, na medida em que tudo o que é atribuído à ideia de humanidade é, ao mesmo tempo, negado aos animais, como a linguagem, a razão, o intelecto e a moral, por exemplo. Ingold (1995) propõe pensarmos os animais enquanto essencialmente iguais aos humanos. 
Estudos Multiespécies: uma breve análise da teoria e de suas aplicações.

Revista Ensaios, vol. 13, jul-dez de 2018. ISSN 2175-0564.

Apesar de muitas confluências teóricas, Ingold se diferencia de Latour na medida em que, em sua concepção, os objetos não podem ser considerados como comparativamente iguais aos organismos vivos, de forma simétrica. Latour, por sua vez, inclui em sua noção de não humanos os objetos e elementos inanimados.

\section{Algumas Perspectivas da relação Humano-Animal dentro da Antropologia}

\section{a) Defensores dos direitos dos animais}

Na perspectiva dos defensores dos animais, segundo Perrota (2016), a pergunta "o que é humano?”, presente desde a antiguidade, inverte-se, tornando-se “o que é o animal?”. Se, para responder a primeira questão, buscou-se diferenciar o humano do animal, a segunda questão faz exatamente o contrário: interessa apontar as semelhanças, sendo o próprio conceito de humanidade ampliado para incluir os animais.

Se na antiguidade havia um debate a respeito da consciência animal, e inclusive filósofos que alegavam a sua existência, tais como Pitágoras e Aristóteles, Sêneca, Ovídio, Porfírio e Plutarco (FELIPE, 2012), a Idade Moderna, é identificada para os defensores dos animais como o período em que não houve mais investigações a respeito da consciência animal, e nem julgamentos de animais em tribunais, dado o predomínio da ideia de que estes seriam desprovidos de razão e qualquer tipo de consciência, portanto destituídos de direitos.

Em seus esforços para a redefinição do animal, seus defensores incorporam e instrumentalizam o entendimento acerca da ética que será discutido sempre na chave da justiça: "Por 'ética', os defensores definem que se trata de um valor que reflete a justiça das ações (...) é tratada como um princípio normativo que regula nossas ações, tendo em vista o outro" (PERROTA, 2016, p. 25-26). Os animais passariam também a serem beneficiados por essa definição. Há, desse modo, um pensamento antiético na sociedade atual, permitindo que se faça mal aos animais. Uma nova definição da ética transformaria essas práticas ao denunciá-las. Faz-se necessário uma mudança de paradigma, que oriente uma nova forma de pensar e agir, instaurando uma regulamentação para o direito, mercado e ciência, capaz de mudar o padrão de vínculo estabelecido entre humanos e não humanos. 
Estudos Multiespécies: uma breve análise da teoria e de suas aplicações.

Revista Ensaios, vol. 13, jul-dez de 2018. ISSN 2175-0564.

Bevilaqua (2019) fala sobre as recentes mudanças nas legislações de diversos países, declarando que os animais não são coisas, sendo a primeira delas a emenda de 2015 do Código Civil francês, que declarou serem os animais dotados de sensibilidade. Em outros casos, no entanto, as reformas ratificaram o estado anterior, segundo o qual os animais devem ser tratados como coisas. A autora argumenta que essas mudanças operam deixando os animais a meio caminho entre pessoa e coisa, "imobilizando-os em um vazio jurídico" (BEVILAQUA, 2016, p.40). Paralelamente a essas mudanças, ativistas têm insistido no reconhecimento jurídico dos animais enquanto pessoas.

Parte importante do trabalho dos ativistas é a exposição das situações de sofrimentos aos quais os animais estão submetidos em nossa sociedade, sobre o qual não possuímos total clareza de informações através dos meios de comunicação, ou simplesmente desprezamos por não se constituir para nós um problema ético. As três principais atividades correntemente denunciadas são: o uso de animais para fins de entretenimento, em rituais religiosos e para a produção de alimentos e vestuário. Em todas elas há, "morte", o "sistema de confinamento", a "vida artificial", a "alimentação forçada", a "tortura", a "violência" e "agressões físicas e psicológicas." (PERROTA, 2016, p.43).

\section{b) O Perspectivismo Ameríndio}

Em seu texto “A Inconstância da Alma Selvagem”, Castro (2002), traça as diferenças contrastantes entre o pensamento dos povos ameríndios e a dos povos ocidentais. A primeira chamou "multiculturalismo", a segunda de "multinaturalismo." Enquanto os povos ocidentais consideram a unicidade da natureza e a pluralidade das culturas, os ameríndios fazem o movimento contrário: a cultura ou o sujeito tomam a forma do universal, enquanto natureza e objeto são particulares e específicos. Soma-se a isso que, no pensamento ameríndio, natureza e cultura configuram, nas palavras de Castro (2002), perspectivas móveis, pontos de vista, e esse fato relaciona-se com a concepção indígena a respeito dos seres não humanos e suas subjetividades.

O perspectivismo implica a capacidade de "ocupar um ponto de vista" (CASTRO, 2002, p.353), ou seja, os animais se veem como pessoas e possuem consciência e uma 
Estudos Multiespécies: uma breve análise da teoria e de suas aplicações.

Revista Ensaios, vol. 13, jul-dez de 2018. ISSN 2175-0564.

perspectiva de enxergar o mundo, tal qual um ser humano. Do mesmo modo, também portam um espírito, este sendo o aspecto que une animais e humanos, já que o corpo se trata de uma aparência variável, específica de cada espécie e que pode servir apenas como roupa ou disfarce. Isso nos leva a outro fato interessante: enquanto, para os povos ocidentais, o homem se diferencia a partir do animal, para os ameríndios o animal veio do homem, e este somente se particulariza ao virar um animal, já que os humanos são seres indiferenciados e presos a sua homogeneidade. Nesse sentido, a natureza se afasta da cultura e não o contrário. Em suma, enquanto na nossa mitologia ocidental imaginamos o homem enquanto ser que outrora foi animal, mas que não perdeu completamente sua animalidade, do mesmo modo as "roupas" animais na verdade escondem uma essência humana espiritual comum, oculta pela animalidade da aparência externa.

Descolas (1998), em seu texto "Estrutura ou sentimento: a relação com o animal na Amazônia", comenta o pensamento das populações amazônicas: "Os animais são com certeza diferentes de nós em sua morfologia e em seu comportamento; contudo, a existência social que eles têm à nossa revelia é idêntica à nossa" (DESCOLAS, 1998, p. 28). Para ele, considerando os mitos, ritos de caça, mediação xamânica da relação com os espíritos, tais práticas comprovam no cotidiano dessas populações, a presença de humanos, plantas e animais em um mesmo plano ontológico.

\section{c) A questão da antropomorfização}

Segundo Mateus e Higuchi (2019), alguns animais são escolhidos para a conservação, por possuírem aspectos físicos e comportamentais homogêneos tolerados ou apreciados pelo ser humano, enquanto que aqueles despossuídos dessas características são rechaçados e afastados do convívio humano. Para os autores, entre essas características determinantes para a escolha da conservação estaria um conjunto de práticas ditas humanas, e a estética ou semelhança antropomórfica. Por antropomorfização os autores entendem o processo pelo qual "animais não-humanos, como os de estimação (pets), são identificados como se fossem pessoas, pois vivem na casa de humanos, onde são tratados como membros de suas famílias." MATEUS e HIGUCHI, 2019, p.180). Desse modo, a domesticação seria um processo de aproximação dos animais já escolhidos para a conservação, ao cotidiano humano. Os 
Estudos Multiespécies: uma breve análise da teoria e de suas aplicações.

Revista Ensaios, vol. 13, jul-dez de 2018. ISSN 2175-0564.

mamíferos e aves têm sido os animais que, por possuírem esses atributos, são o maior alvo de proteção humana.

Segundo Descolas (1998), os direitos atribuídos aos animais respeitam uma escala de valor, baseada no antropocentrismo, capacidade de identificação com o animal segundo sua proximidade com o ser humano, referenciada em uma escala, geralmente inconsciente, de valor. No topo dessa escala, estão aquelas espécies mais próximas do ser humano, nos quesitos comportamentais, fisiológicos, emocionais ou das faculdades cognitivas.

Esse pensamento tem suas bases nas distinções homem/animal de pensadores do final do século XVIII, como Kant e Rousseau, que definem a humanidade pela capacidade de não se determinar por relações de instinto. Assim sendo, nossa atribuição de direitos e respeito aos animais ocorre de maneira mais enfática àqueles que são capazes de agir com intenção direcionada a um fim consciente, ou seja, "devemos respeitar neles aquilo que nos leva a respeitar a nós mesmos" (DESCOLAS, 1998, p. 33). As cosmologias amazônicas, por sua vez, diferem do dualismo moderno ao estabelecerem uma diferença de grau, e não de natureza, às espécies humanas e não humanas.

Lima (2015), a respeito deste tema, contrapõe dois argumentos de Descolas (1998): o primeiro é que os defensores dos direitos dos animais defendem os mamíferos em particular por associação à sua proximidade em relação aos humanos, percebidos como semelhantes, e o segundo, sobre a definição de antropomorfização, que para Descolas significa atribuir emoções e sensibilidade a animais não humanos. Para Lima (2015) o primeiro argumento desconsidera um processo histórico de aumento gradual de sensibilização com relação à violência e que não haveria nada de excepcional no fato de que essa ampliação se deu primeiro a outros seres entendidos como sensíveis. O segundo argumento, julgando ser antropocêntrico e cartesiano na medida em que afirma que animais não possuem emoções ou sensibilidade, desconsiderando a produção acadêmica de diversas disciplinas demonstrando a capacidade de mamíferos e aves, por serem dotados de sistema nervoso central, formar laços afetivos, sentir emoções e dor (LIMA, 2015).

A autora tece uma distinção entre os termos antropomorfização e humanização, por considerar que o estudo dessas relações exige uma conceituação mais precisa. O primeiro seria uma conceituação pejorativa, remetendo à adequação estética aos padrões e modas 
Estudos Multiespécies: uma breve análise da teoria e de suas aplicações.

Revista Ensaios, vol. 13, jul-dez de 2018. ISSN 2175-0564.

humanos, e o segundo refere-se à emoção, e pode ser utilizado para tratar de transformações na moralidade e da atribuição de estados mentais humanos a animais não humanos. A convivência, o envolvimento afetivo, o próprio mercado pet, são fatores preponderantes para o crescimento da sensibilidade humanizante em relação aos animais, enxergada como mudança positiva.

Para Van Dooren (2016) o antropomorfismo é uma acusação pejorativa que encerra a discussão ao invés de aprofundá-la criticamente a respeito da forma como características podem ser compartilhadas entre humanos e não humanos. Estudiosos multiespécies utilizam narrativas ricas em anedotas e metáforas, e esse recurso pode ser muito eficiente, permitindonos “mover para fora de um espaço estreito de 'comportamentos típicos de espécie' para reconhecer a diversidade individual ou social e a capacidade criativa dentro de outros modos de vida." (VAN DOOREN, 2016, p.45).

\section{Os estudos multiespécies}

Depois de situar o debate da dicotomia natureza e cultura, subjacente ao conteúdo pertinente a este artigo, e de abordar algumas perspectivas teóricas da relação humanoanimal, nesta seção pretendo adentrar de fato o debate dos estudos multiespécies, de modo a introduzir o leitor à proposta dessa complexa teoria antropológica e ao mesmo tempo multidisciplinar.

A corrente multiespécie reitera que as ciências naturais estão longe de ser a única forma de conhecer as vidas de outras espécies. Para isso, concentra-se em estudar as relações construídas entre indivíduos de espécies biológicas diferentes, partindo de conceitos presentes dentro das ciências sociais e rompendo, com a barreira, antes imposta, entre o que seria objeto de estudo das ciências humanas e o que seria competente às ciências biológicas. Ela toma para si a observação através da imersão etnográfica nos modos de vida de seres, antes deixados às margens dos estudos antropológicos - tais como animais, plantas e fungos -, e preocupa-se em entender as relações construídas entre diferentes espécies que se entrelaçam dentro do mesmo ambiente. 
A inserção dos estudos multiespécies nas ciências sociais deu-se a partir do questionamento ao modelo tradicional das teorias antropológicas, focadas em estudar apenas as relações entre os seres humanos quando reunidos em comunidades - e acreditando que, dessa forma, seria possível compreender essas relações completamente. Indo além, essa teoria acredita que é necessário olhar para outras formas de vida, uma vez que elas interagem e criam relações com os seres humanos.

Segundo Van Dooren (2016), dentro dos estudos multiespécie, o termo "espécie" remete a modos de vida particulares e qualquer reunião relevante de um conjunto de parentes ou tipos. Esses conjuntos não são homogêneos nem fixos, e estão em constante movimento ativo de associação e dissociação, de modelagem e remodelagem. As associações carregam consigo uma multiplicidade de significados, complexos e mutáveis, que constituem um importante alvo de estudo.

Diferentemente dos pesquisadores do "animal studies", que em sua maioria têm se concentrado no estudo das relações entre um determinado animal e o ser humano, a abordagem multiespécies procura observar as multidões de agentes animados que fazem com que eles estejam em meio a relações emaranhadas que incluem, mas sempre também excedem, dinâmicas de predador e presa, parasita e hospedeiro, pesquisador e pesquisado (Van DOOREN, 2016). Os etnógrafos multiespécies estudam o acolhimento de vidas e mortes que estão ligadas a mundos sociais humanos: buscam entender que efeitos causam e por onde são afetados, dentro dos âmbitos políticos, sociais e culturais.

A partir, dessas reflexões, estudiosos multiespécies estão reformulando algumas questões políticas, sociais e culturais. Extinção em massa, mudanças climáticas, globalização terrorismo, colonialismo e o capitalismo devem ser pensados nas suas relações de poder desiguais, situadas em uma teia de vida mais ampla. Nas palavras de Van Dooren: "Histórias apenas-humanas não servirão a ninguém em uma época modelada pelo agravamento e fortalecimento mútuo de processos de destruição biossocial.” (Van DOOREN, 2016, p.41).

Para isso, esses estudiosos, exploram questões vitais através da imersão na pesquisa interdisciplinar e com um escopo taxonômico mais amplo de investigação, explorando uma complexa "ecologia de seres" (KHON, 2013). A possibilidade de campo de pesquisa se expande, tendo em vista a vivacidade do abiótico, das formações geológicas, aos rios e 
Estudos Multiespécies: uma breve análise da teoria e de suas aplicações.

Revista Ensaios, vol. 13, jul-dez de 2018. ISSN 2175-0564.

geleiras. Essas entidades são pensadas como capazes de possuir modos de vidas, uma história particular, afetar e serem afetados. Não se trata, desse modo, da escolha de um animal específico ou de um conjunto de animais, como se propôs em outras perspectivas teóricas, mas a multiplicidade de perspectivas e influências é a chave de entendimento dos estudos multiespécies.

Esta perspectiva teórica não nos fornece apenas uma nova representação da vida não humana, mas também uma nova apreciação e compreensão do próprio humano, desde o organismo individual até a própria espécie de modo geral. Descobertas recentes revelaram que os corpos humanos são cheios de vida parasita e simbiótica (HARAWAY, 2016), os corpos são eles próprios multiplicidades de seres coexistindo, e não há um único humano que exista em isolamento do mundo mais amplo. Sabendo disso, importa compreender a especificidade da aproximação e das conexões estabelecidas.

A ética é uma questão primordial para a perspectiva teórica aqui colocada: "as abordagens multiespécies estão fundamentadas no entendimento de que a atenção cuidadosa às diversas formas de ser e de tornar-se é inseparável do trabalho da ética." (Van DOOREN, 2016, p.52). Está no cerne das narrativas produzidas construir melhores possibilidades de uma vida compartilhada.

\section{Algumas aplicações dos estudos multiespécies:}

\section{a) Etnografia a partir de Cogumelos e Florestas}

Nesta seção pretende-se comentar brevemente e, ao final, tecer algumas relações entre dois textos relativamente recentes e desenvolvidos através da imersão etnográfica na vida dos seres não humanos. São eles: "How Forests Think", de Eduardo Kohn (2013) e "Margens Indomáveis: cogumelos como espécies companheiras", da autora Anna Tsing.

Eduardo Kohn (2013), ao pensar ontologicamente, produz em seu livro uma redefinição de conceitos basilares para a antropologia, como o de representação e pensamento, que surgem a partir de sua prolongada imersão no grupo Runa, residente em Ávila, no Equador. Seu principal objetivo é capacitar a antropologia a pensar por si, formular teses gerais sobre o 
Estudos Multiespécies: uma breve análise da teoria e de suas aplicações.

Revista Ensaios, vol. 13, jul-dez de 2018. ISSN 2175-0564.

mundo, ou sobre a natureza da realidade, e se tornar algo mais do que apenas uma teoria sobre o entendimento alheio. Desse modo, a questão colocada pelo livro é sobre como as "florestas pensam, e não sobre como os nativos pensam que a floresta pensa" (MATOS, 2015, p.481).

Um dos pontos de partida de Kohn é superar a concepção segundo a qual a capacidade de pensamento e representação seria restrita apenas à mente humana, e não uma propriedade do mundo, sendo esta a forma como os Runa de Ávila compreendem o universo ao seu redor. O objetivo de Kohn, no entanto, não é exatamente estudar como os Runa pensam, mas o ponto de vista do mundo em que eles vivem.

O primeiro passo importante na direção de entender como outros organismos, que não o humano, pensam é ampliar o sentido do conceito de representação, para além do linguístico e simbólico. Kohn argumenta que os signos não resultam de processos indiferenciados internos a cada organismo, ou mesmo de uma natureza mecânica individual de cada espécie, mas que, na medida em que são interpretados por um outro, resultam de hábitos compartilhados entre os seres vivos, fazendo parte de um processo relacional.

É nesse sentido que "A floresta tropical é para ele uma teia proliferante de hábitos que evoluíram conjuntamente, de tal modo que ela se converte em uma complexa entidade viva, por isso capaz de pensar" (SOUZA, 2015, p.414). A capacidade da antropologia de formular teses gerais sobre o mundo se daria justamente pelo fato da generalidade ser uma propriedade do mundo, formada pelo emaranhamento de seres e organismos que evoluem em relação uns com os outros, produzindo cadeias de similaridades.

A possibilidade de compreensão e descrição desse pensamento de tudo que é vivo se dá, portanto, através das relações íntimas e atentas, capazes de se desenvolver com a convivência: "por mais que os humanos gozem de relações íntimas com seus cães, por exemplo, eles nunca sabem com total certeza o que os cachorros pensam. Contudo, eles podem ter bons palpites sobre isso" (SOUZA, 2015, p.414). Embora a compreensão absoluta não seja um dado tomado por certo, o distanciamento causado pela possível existência de diferenças irredutíveis tampouco nos permite continuar superando obstáculos. 
O grupo Runa da Ávila, que Kohn descreve, parte de pressupostos ontológicos, no sentido que Castro (2002) chamou de "perspectivismo" dos povos ameríndios. Para eles, todos os seres possuem alma e veem a si mesmos como pessoas. Kohn explica que essa forma de compreender o mundo ao redor é uma resposta à necessidade de interagir com a ecologia das florestas, que requer não necessariamente simetria, mas, sem dúvida, intimidade e sintonia.

Para Kohn, olhar para os Runa é conhecer apenas uma orientação particular de conceber o mundo, à antropologia estaria a tarefa de determinar a realidade para além do humano, pois esse conhecimento nos leva à compreensão daquilo que nos faz ser os seres que somos e também o nosso devir.

Segundo Tsing (2015, p.182) os cogumelos "são bem conhecidos como companheiros" vivendo em diversos tipos de associações interespecíficas. Associam-se com raízes de plantas, que vivem exclusivamente dos nutrientes recebidos dos fungos, estabelecem relação de simbiose com algas, possibilitando sua sobrevivência em condições extremas, perfuram pedras de modo a tornar minerais disponíveis para outras plantas. Também podem ser patogênicos, no entanto, parecem ser altamente companheiros de outras espécies e ilustram, através de seu modo de vida, a interdependência entre as espécies.

A pesquisa de Tsing a respeito dos cogumelos e seu caráter de companheirismo suscita uma série de reflexões a respeito da natureza humana. Uma delas é a questão da interdependência entre as espécies. A autora afirma ser a natureza humana "uma relação entre espécies" (TSING, 2015, p.184). As práticas humanas, tanto culturais quanto históricas, não podem ser consideradas autônomas, esse pensamento teria alimentado nossos ideais de controle sobre a natureza, assim como ideologias autocráticas e militaristas.

Um outro ponto de sua reflexão é a questão da domesticação, entendida sempre como uma dicotomia entre o animal selvagem e o humano que o controla e domina, ignorando as complexas relações de dependência que fazem ambos os lados da dicotomia serem afetados, além dos impactos dessa atitude egoísta, que podem ser devastadores, da homogeneização genética à destruição da paisagem multiespécie. A prática da domesticação nos impede de perceber os modos interespecíficos de ser das espécies. 
Estudos Multiespécies: uma breve análise da teoria e de suas aplicações.

Revista Ensaios, vol. 13, jul-dez de 2018. ISSN 2175-0564.

Poucos fungos foram objeto de domesticação, não obstante são um indicativo da condição humana. Tsing nos dá exemplos da presença dos fungos em diversas práticas humanas e como nas mudanças dessas práticas eles estiveram implicados, de modo que seria possível contar a história humana a partir da história dos fungos. É isso que a autora faz ao abordar a história da monocultura, das plantations e do agronegócio, através da atuação, determinante em todos esses processos, dos fungos, tanto no antigo Oriente Próximo, com a produção Estatal intensiva de cereais, passando pelas batatas irlandesas, até chegar à expansão colonizadora europeia, baseada na empresa monocultora. Tsing nos mostra como os fungos direcionaram o sentido da História, por serem adversários tanto da monocultura quanto dos monocultores, criaram a reputação de inimigos da civilização pelas suas incursões devastadoras contra essa forma de padronização de seus ambientes multiespécies e moldaram as estratégias de seus oponentes. A persistência da existência da diversidade de espécies e populações é um dado que espanta.

\begin{abstract}
A diversidade, biológica e social, se amontoa defensivamente em margens despercebidas (...). De fato, na maioria dos lugares existe uma correlação negativa entre, de um lado, a diversidade e, de outro, a intensidade de investimento de capital e controle do Estado. Para aqueles que amam a diversidade, talvez seja necessário um projeto de desmapeamento do Capital-Estado (TISING, 2015, p.193)
\end{abstract}

Tsing, assim como Kohn, nos mostra o quanto os seres não humanos têm a dizer sobre a condição humana. A partir do texto "Margens Indomáveis: cogumelos como espécies companheiras", aqui brevemente comentado, compreendemos parte importante da história da humanidade a partir dos fungos, e também o quanto seu modo de vida, extremamente associativo, ilustra a interdependência das espécies. Kohn, ao falar da floresta e de como todos os seres evoluíram conjuntamente e por isso possuem histórias entrelaçadas, demonstra o quanto os não humanos têm muito a dizer sobre a existência humana e seu devir. Para acessar esse conhecimento, no entanto, precisamos reconhecer que são passíveis de representar, pensar e se comunicar, e isso requer intimidade e convivência.

b) A relação entre animais humanos pesquisadores e animais não humanos como instrumentos de pesquisa 
Nesta parte do artigo, comentarei trabalhos de campo que investigam a relação entre pesquisadores e animais de laboratório, partindo das noções teóricas construídas pela literatura multiespécies na antropologia. Um deles é o "Vidas Experimentais: humanos e roedores no laboratório," e o outro "Experiência e Descarte: dores humanas e não humanas em um laboratório de neurotoxicidade e psicofarmacologia".

O primeiro estudo trata das relações entre pesquisadores e roedores em um laboratório e biotério pertencentes a uma instituição pública brasileira. A discussão tem início em torno da histórica relação entre humanos e animais no que diz respeito à sua descrição pelos estudos sociais: de início a relação enxergada era de apenas utilidade material, ou os animais são "bons para comer", o que posteriormente a crítica ao reducionismo utilitarista conduziu ao campo do simbólico, ou os animais são "bons para pensar", mas ainda assim objetos passivos frente às intenções e ações humanas. A crítica atual incide justamente nesse ponto, na tentativa de subverter essa lógica de pensamento colocando os animais como entidades ativas e plenas de direito nas sociedades humanas, assim como os próprios humanos enquanto dependentes das conexões estabelecidas com outros seres vivos.

Os roedores são os animais experimentais mais utilizados nas pesquisas em ciências da vida, mas nem sempre foi assim. Um número muito variado de espécies já foi empregado no trabalho científico, tais como: rãs, cavalos, vacas, vermes, entre outros. O camundongo só irá se instalar como animal de laboratório preferencial durante o período de 1900 e 1955. A principal preferência em torno deles se deveu a vários fatores, tais como: serem pequenos, fáceis de manusear, reprodução célere, e também o fato de serem acometidos por várias doenças pelos quais os serem humanos também padecem (câncer, diabetes etc.). Mas o mais importante foi o processo crucial de conversão do camundongo em organismo padronizado para a pesquisa biomédica, através de cruzamentos seguidos entre irmãos, por muitas e muitas gerações, até que os camundongos usados no laboratório se transformassem nos seres materialmente homogêneos e invariáveis que são hoje.

Segundo a descrição de Souza (2013), os animais usualmente vão para a sala de experimentação saudáveis, exceto que sejam diabéticos selecionados geneticamente, sendo levados a adquirir alguma enfermidade para que os pesquisadores possam analisar as consequências de uma determinada condição sobre os órgãos vitais. Para a conclusão da 
Estudos Multiespécies: uma breve análise da teoria e de suas aplicações.

Revista Ensaios, vol. 13, jul-dez de 2018. ISSN 2175-0564.

pesquisa, se faz necessária a morte do animal, pois além da descrição dos resultados, são também acrescentadas provas para sustentar a conclusão de uma investigação. "O experimento confere ao experimentador o direito de falar em nome das coisas, ele é sua fonte de autoridade" (STENGERS, 2002 apud SOUZA, 2013, p.260). O animal, mesmo recuperado de uma doença grave através do procedimento, deve perecer para que se possa produzir as evidências amostrais necessárias de tecidos retiradas do corpo do animal, fragmentos que serão depois preparados, fotografados, congelados e constarão nos relatórios e artigos escritos pelos pesquisadores.

O artigo "Experiência e descarte: dores humanas e não humanas" nos traz uma experiência etnográfica em um laboratório de neurotoxicidade e psicofarmacologia de uma universidade brasileira, através do qual tece uma descrição sobre o espaço e os agentes que nele atuam, colocando ênfase em analisar as formas de classificação e categorização do evento-conceito dor, construído e inscrito no ambiente de laboratório.

No experimento presenciado por esse estudo, o pesquisador impinge dor nas cobaias de modo a criar nos animais condições próximas ao que seria sentido pelos humanos. Nesse contexto, o autor nos mostra como essa intervenção objetiva representar dores humanas em sujeitos animais para artificialmente naturalizá-los em algo de humano, quando, ao mesmo tempo, as outras formas de dores sentidas pelos animais em decorrência do estudo as quais não fazem parte do escopo da pesquisa, são totalmente desconsideradas, mesmo também fazendo parte das vivências de sujeitos humanos. Nessa passagem, Sá (2011) cita uma ideia pertinente de Donna Haraway contida em seu artigo "Sharing suffering": "A dor não pode ser, nesse caso, suportada simetricamente, ela é consequência de práticas historicamente situadas de distinção hierárquica que tornam uns "matáveis' e outros não." (HARAWAY, 2008 apud SÁ, 2011, p.432).

A respeito do experimento e do uso dos animais, esse artigo argumenta que "o que impera no discurso dos pesquisadores dá conta de que as cobaias devem ser utilizadas ao máximo antes de serem descartadas" (SÁ, 2011, p.431), ou seja, o respeito pela preservação da vida desses animais só existe na medida em que é construída através de uma lógica utilitarista e de descarte. 
De outro modo, sobre o sacrifício e manuseio de animais, Souza nos mostra que o animal no laboratório é considerado um recurso a ser usado com parcimônia, dado que sua obtenção, manutenção e uso precede uma sequência de ações sistematizadas, que devem ser obedecidas, sendo necessário que o projeto seja examinado e aprovado pela Comissão de Ética no Uso de Animais (CEUA), centro que avalia se os procedimentos propostos são apropriados. A propósito, o rigor da avaliação conduziu a um decréscimo significativo na produção de camundongos e ratos a serem utilizados no biotério pesquisado, segundo informações do responsável.

A conversa com alguns responsáveis pelos experimentos nos indica que, para os pesquisadores, a realização de procedimentos que ferem e causa doença e dor não são tão problemáticas quanto o sacrifício. Nessa passagem, Souza cita o autor Lynch (1988), para o qual o sacrifício é um dos aspectos centrais no trabalho com animais em laboratório. Segundo ele, os animais passam por uma realização de rituais de purificação para que a passagem do "animal naturalístico" para o "animal analítico" possa se concretizar. Após a purificação, as partes do corpo do animal são finalmente transformadas em artefatos de laboratório, portanto, convertidas em dados.

A fim de compreender o processo de produção do conhecimento e o lugar central que o sacrifício representa nessa construção, Lynch aponta o termo sacrifício como expressão de um discurso sacralizador, que carrega um duplo sentido: o primeiro diz respeito ao fato de que a morte do animal seria um sacrifício em nome de interesses mais elevados, como a cura de doenças ou o próprio avanço da ciência; o segundo sentido estaria na conversão do animal em objeto sagrado da investigação científica.

No contexto da prática observada, percebemos que a literatura multiespécie, segundo a qual há um entrelaçamento e uma intersecção entre os viventes, se efetiva, dado que, do mesmo modo em que o animal de laboratório é feito no biotério pelos humanos através de uma série de procedimentos pormenorizados e sistematizados - tais como homogeneização genética, proteção de enfermidades, introdução de doenças específicas e etc, -, um certo tipo de pesquisador também é produzido pelos animais, pois tornar-se cientista dentro desse contexto de relação com os animais é, como nos mostra Souza, 
Estudos Multiespécies: uma breve análise da teoria e de suas aplicações.

Revista Ensaios, vol. 13, jul-dez de 2018. ISSN 2175-0564.

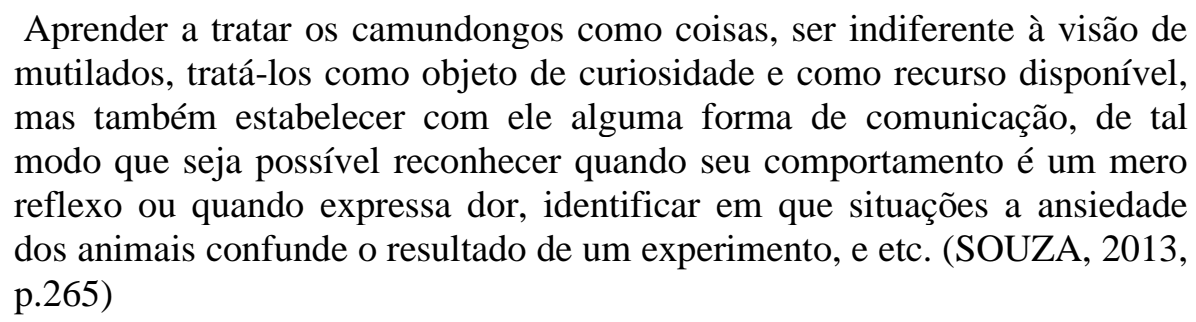

O distanciamento entre sujeitos humanos (pesquisadores, no caso) e animais ocorre, mas há também um engajamento com relação ao animal, que envolve uma consideração de suas especificidades e um cuidado com o seu bem-estar, visto que, para que a pesquisa chegue a um bom termo, essas preocupações são imprescindíveis. Para ambas as pesquisas aqui citadas, pesquisadores e animais de pesquisa se fazem conjuntamente, e, com efeito, o entrelaçamento está sempre presente, não havendo passividade de lado algum.

\section{Considerações Finais}

De modo geral, este artigo pretendeu introduzir o leitor ao que se convencionou chamar por estudos multiespécies. Primeiramente através da apresentação de temas, tais como a clássica dicotomia entre natureza e cultura, algumas perspectivas da relação humano-animal; textos que inserem os conceitos e o escopo pertinente a esta literatura específica e, finalmente, através da imersão em campos de estudos que fazem parte da teoria multiespécie, ou seja, possuem por objetivo investigar a relação entre humanos e animais não humanos no que diz respeito aos seus entrelaçamentos e assimetrias, por intermédio de uma descrição pormenorizada do dia-a-dia e da relação estabelecida entre ambos.

Tecerei alguns comentários a respeito das etnografias abordadas a partir da quinta seção. Eduardo Kohn (2013) chama atenção não somente pelo título de seu livro, que logo aguça a curiosidade, mas também pelo objetivo de irromper uma virada ontológica na antropologia. Ao propor que esta se volte aos grandes objetivos de entendimento do mundo, como as teorias gerais, para além das concepções particulares dos nativos que estuda, me parece que ele retorna a uma ciência humana que enxerga o humano superestimado, capaz de tomar os nativos ao qual se dedica como meros instrumentos de seus objetivos teóricos mais sublimes. Às ciências da natureza, entregamos o papel de formular teorias totalizantes, enquanto as ciências humanas já superaram essa fase. 
Estudos Multiespécies: uma breve análise da teoria e de suas aplicações.

Revista Ensaios, vol. 13, jul-dez de 2018. ISSN 2175-0564.

Há dois pontos altos do texto de Tsing (2015): o primeiro é a forma como ela argumenta que o modo de vida dos fungos seria ilustrativo da interdependência das espécies de modo geral, e o segundo quando aponta uma correlação negativa entre a diversidade das espécies de um lado, e do outro a intensidade de investimento de capital e controle do Estado. A relação da história humana a partir da história dos fungos me pareceu, no entanto, que poderia ser melhor desenvolvida. Os humanos ganharam toda a ênfase da exposição histórica, os fungos poderiam ser colocados mais em evidência, de modo a corroborar com a proposta que a própria autora faz em seu texto. Como proposta para outros estudos, esse texto é, sem dúvida, inspirador.

A relação entre animais de laboratório e pesquisadores permitiu perceber as assimetrias presentes e indissociáveis no trato com os animais, aqui representados pelo conceito de natureza, ou seja, distanciados e purificados daquilo que seria o conceito opositor, a sociedade. Historicamente, construímos um modo específico de se relacionar com aquilo que designamos por natureza, estabelecendo também a quantidade de respeito e responsabilidade que teríamos para com esta parte do nosso universo. Aqui cito novamente Donna Haraway (2011), segundo o qual existe uma distinção hierárquica que torna uns "matáveis" e outros não.

É interessante notar que apesar de serem tratados enquanto natureza, os ratos de laboratório são extremamente artificiais, dado que são produto de inúmeras intervenções laboratoriais, desde o cruzamento entre irmãos e a preparação de um habitat pormenorizadamente específico, de modo a produzir um animal compatível com as necessidades da análise, até a indução a certas doenças para a execução das pesquisas. São tratados enquanto natureza para se encaixarem dentro da constituição ética que permitem aos humanos os utilizarem para seus próprios fins, sem que para isso necessitem infringir qualquer lei ou padrão ético de suas instituições. Essas são algumas das considerações que se achou importante ressaltar ao final desse artigo para fins de reflexão. Os estudos multiespécies são, sobretudo, uma forma de estar atento e conceber o universo, e tudo o que lhe diz respeito, de um modo mais responsável e simétrico.

\section{Referências:}


Estudos Multiespécies: uma breve análise da teoria e de suas aplicações.

Revista Ensaios, vol. 13, jul-dez de 2018. ISSN 2175-0564.

ANDRADE, Berlano Bênis França. Os desdobramentos do debate sobre os conceitos de natureza e cultura em Tim Ingold. REIA- Revista de Estudos e Investigações Antropológicas, Pernambuco, ano 3, volume Especial I, p.23-33, 2016. Disponível em: <https://periodicos.ufpe.br/revistas/reia/article/view/229990/24178> Acesso em: 05.out. 2019

BEVILAQUA, Ciméa Barbato. Pessoas não humanas: Sandra, Cecília e a emergência de novas formas de existência jurídica. Mana [online], Rio de Janeiro, vol.25, n.1, p.38-71, 2019. Disponível em: <http://www.scielo.br/scielo.php?script=sci_arttext\&pid=S010493132019000100038> Acesso em: 05.out. 2019.

CASTRO, Eduardo Viveiro de. A inconstância da alma selvagem. $5^{\circ}$. ed. São Paulo: Cosac \& Naify, 2013. 552 p.

FELIPE, Sonia. Consciência na neurociência [S.I.] Agência de Notícias de Direitos Animais, 2012. Disponível em: 〈http:/www.anda.jor.br/19/09/2012/consciencia-na-neurociencia > Acesso em: 24.jun.2018.

FREIRE, Leticia de Luna. Seguindo Bruno Latour: Notas para uma antropologia simétrica. Revista Comum, Rio de Janeiro, v.11, n²6 , p.46-65, 2006. Disponível em: <http://lemetro.ifcs.ufrj.br/pesquisadores/Leticia\%20de\%20Luna\%20Freire/latour.pdf>

Acesso em 28.out.2018

HARAWAY, Donna A partilha do sofrimento: Relações Instrumentais entre animais de laboratório e sua gente. Horizontes Antropológicos, Porto Alegre, ano 17, n.35, p.27-64, 2011

Staying with the trouble: making kin in the Chthulhucene. Durham and London: Duke University Press, 2016. 312 p.

INGOLD, Tim. Humanidade e animalidade. Trad. Vera Pereira. Revista Brasileira de Ciências Sociais, v. 28, n. 10, p. 39-53, 1995. Disponível em: <http://www.iea.usp.br/eventos/ingold-humanidade>. Acesso em: 25 set. 2019.

Gente como a gente: $\mathrm{O}$ conceito de homem anatomicamente moderno. Ponto Urbe. Edição [Online], 9, 2011. Discponível em: 〈http://journals.openedition.org/pontourbe/1823> Acesso em: 05.out. 2019.

Sobre A Distinção Entre Evolução e História. Revista Antropolítica, Rio de Janeiro, n. 20, p.17-36, 2006.

KOHN, Eduardo. How Forests Think: Toward an anthropology beyond the human. Berkeley: University of California Press, 2013, 267 p.

LATOUR, Bruno. Jamais fomos modernos: ensaio de antropologia simétrica. Rio de Janeiro: Editora 34, 1994, 152 p.

LIMA, M. H. C. C. A. Considerações sobre a família multiespécie. V Reunião Equatorial de Antropologia (REA) e XIV Reunião de Antropólogos do Norte e Nordeste (ABANNE), UFSC, Maceió, 2015. Disponível em: http://www.evento.ufal.br/anaisreaabanne/gt06_c.php Acesso em: 05.out. 2019. 
Estudos Multiespécies: uma breve análise da teoria e de suas aplicações.

Revista Ensaios, vol. 13, jul-dez de 2018. ISSN 2175-0564.

LYNCH, Michael, Sacrifice and the transformation of the animal into a scientific object: laboratory culture and ritual practices in the neuroscience. Social Studies of Science, 18: 265289, 1988.

MATEUS, W. D. M. e HIGUCHI, M.I.G. Aspectos da relação pessoa-animal na conservação da fauna silvestre amazônica em risco de extinção. Revista de Educação Ambiental. Rio Grande do Sul,, Vol.24, n.1, p.166-194, 2019.

MATOS, Marcos Almeida. Sobre Como as Florestas Pensam. Revista de Antropologia, São Paulo, Vol. 58, n.1, p.481-490, 2015.

PERROTA, Ana Paula. 'Quem' ou 'o que' são os animais? Um estudo sobre como os defensores dos animais (re)definem sua natureza. Iluminuras, Porto Alegre, v. 17, n.42, p. 17$50,2016$.

SÁ, Guilherme José da Silva, MEDEIROS, Márcio Felipe Salles e SCHIRMANN, Jonas Silva, "Experiência e descarte: dores humanas e não humanas em um laboratório de neurotoxicidade e psicofarmacologia", Revista Sociedade e Cultura, Goiás, 14 (2): p. 427 434, 2012.

SOUZA, Iara Maria de Almeida. Vidas experimentais: humanos e roedores no laboratório, Etnográfica [Online], vol. 17 (2), 2013. Disponível em:

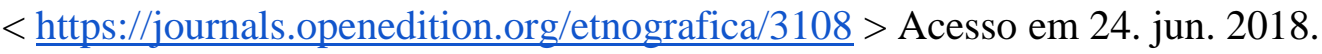

How forests think: toward an anthropology beyond the human. Revista Horizontes Antropológicos, Porto Alegre, ano 21, n. 43, p. 411-416, 2015.

STENGERS, Isabelle, A Invenção das Ciências Modernas. Rio de Janeiro, Editora 34, 2002, $205 \mathrm{p}$.

SUSSEKIND, Felipe. Sobre a vida multiespécie. Revista do Instituto de Estudos Brasileiros, São Paulo, n.69, p. 159-178, 2018 Disponível em: <http://www.scielo.br/scielo.php?script=sci_arttext\&pid=S0020-

38742018000100159\&lng=en\&nrm=iso> Acesso em 24.jun.2018.

TSING, Anna. Margens Indomáveis: cogumelos como espécies companheiras. Ilha Revista de Antropologia, Santa Catarina, v.17, n.1, p.177-201, 2015.

DOOREN, Thom Van, KIRSKEY, Eben; MUNSTER, Úrsula. Estudos multiespécies: cultivando artes de atentividade. Trad. Susana Oliveira Dias. ClimaCom [online], Campinas, Incertezas, ano. 3, n. 7, pp.39-66, 2016. Disponível em: <http://climacom.mudancasclimaticas.net.br/wp-content/uploads/2014/12/07-Incertezas-nov2016.pdf> acessado em 24.jun.2018. 